\title{
Training Translators for Video Game Localization: In Search of a Pedagogical Approach
}

\section{Formando tradutores para a localização de jogos eletrônicos: em busca de uma abordagem pedagógica}

\author{
Marileide Dias Esqueda* \\ *Universidade Federal de Uberlândia (UFU), Uberlândia, Minas Gerais / Brasil \\ marileide.esqueda@ufu.br
}

https://orcid.org/0000-0002-6941-7926

\begin{abstract}
Based on the assumption that video game localization inevitably has levels of collaboration among their agents, forming a collaborative continum that involves localization managers, translators, localization coordinators, and linguistic testers, who directly or indirectly influence the game to be localized, game localization teaching can also adopt a collaborative approach, dynamically promoting experience exchanges between translation teachers and students, and other collaborators. Accordingly, this paper, conceived as a didactic proposal of qualitative and naturalistic bias (GILE, 2009; CHESTERMAN; WILLIAMS, 2002), describes possibilities for incorporating video game localization in translation teaching using a collaborative pedagogical approach (KIRALY, 2000).
\end{abstract}

KEYWORDS: translation teaching; collaborative pedagogy; video game translation and localization; open source tools; free translation memory systems.

RESUMO: Partindo do pressuposto de que a localização de jogos inevitavelmente tem níveis de colaboração entre seus agentes, formando um continuum colaborativo que envolve os gerentes de localização, os tradutores, os coordenadores de localização, bem como os profissionais que testam linguisticamente os jogos, e que direta ou indiretamente influenciam o jogo a ser localizado, o ensino da localização de jogos também pode adotar uma abordagem colaborativa, promovendo dinamicamente a troca de experiências entre professores e alunos de Tradução e outros colaboradores. Nesse sentido, este artigo, concebido como uma proposta didática de viés qualitativo e naturalista (GILE, 2009; CHESTERMAN; WILLIAMS, 2002), descreve possibilidades para a incorporação da localização de jogos no ensino de Tradução, a partir da adoção de uma pedagogia colaborativa (KIRALY, 2000).

PALAVRAS-CHAVE: ensino de tradução; pedagogia colaborativa; tradução e localização de jogos; ferramentas open source; sistemas livres de memória de tradução. 


\section{Introduction}

Broadly speaking, localization is the process involving the preparation, manipulation, engineering, and quality control of utilitarian or entertainment software, i.e., video games, and websites. The term locale, or location, is the combination of a socio-cultural region with a language. It refers to the process by which products and Internet services are modified to be used in different regions. Taking Brazil as an example, one can adapt an American utilitarian or entertainment software to be used in the country, which requires several technical, legal, and cultural adaptations. A locale is not a language, although language is one of the vital components of localization. Technically speaking, locales are represented by a two-letter code combined with the country code, as in the case of pt-BR, or pt-PT, to designate Brazilian Portuguese and Portuguese of Portugal, for example. Localizing a product means adapting it technically and linguistically, with translation being one single and crucial part of the localization process (DUNNE, 2015).

When it comes to video games, the localization process encompasses not only translating the linguistic material of a game into new languages, removing all elements that other cultures might not tolerate in their contexts, but also technically adapting the entire product to fit the requirements of other countries. In this regard, video game localization becomes a massive collaborative effort between developers, translators, and localizers.

The video game localization team has to draw attention to the fact that the main goal is to immerse players in the game, no matter what language they speak, taking group decisions in regard to the scope of the project. The team has to determine, for example, if the game will have a partial localization, where only the text is translated and graphical user interface (UI) and icons remain as in the original, or a full localization, where everything, including the UI, icons, and texts, will be modified. In full localization, even the story of the game can be rewritten in order to match the requirements of the target culture, which demands intense teamwork.

Jelača (2019) explains that the Localization Maturity Model (LMM) is a method, brought to the localization industry in 2006 by the American company, Common Sense Advisory, to measure the maturity of an organization and their respective localization teams: 
It is utilized throughout the industry as a great method to see how teams and organizations can improve their workflows and deliver more quality content to their users. There are nine phases in the LMM model, from -3 to 5 , with 5 being the highest level of maturity. Level 1, or Reactive, means that roles and responsibilities are unclear, localization gets done when it needs to without too much planning. It's basically just putting out fires when they arise. Level 2, or Repeatable, starts to show the usage of some basic workflows, and the use of outsourcers. Level 3, or Managed, means that processes and workflows are set up and used, as well as localization tools. Depending on the setup of the team and organization, localization work is either centralized or spread throughout the company. Level 4, or Optimized, means that standards are followed throughout the company, documentation is kept up to date, and probably the most meaningful of all: localization is accepted as one of the key pillars of product and company success. Level 5, or Transparent, means that localization is a central part of company plannings and product launches, the team is able to scale the work, and metrics are being followed and met. (JELAČA, 2019, p. 26).

As pointed out by Jelača (2019), teamwork in the localization field means not only designing the group's own style guide, terminology, and technical requirements, but also deciding on workflows, as well as on the localization tools to be used during the process.

Calek (2019) states that:

If a game has a lot of specific characteristics, chances are high that there will be a team of managers, engineers, localizers, terminologists, translators working on a single project. This makes a kind of "coordinated creativity" necessary. Communication, a well-kept, shared terminology database and translation memory, proofreading and QA can help achieve consistent and immersive results, but it does take a lot of effort and very thorough translators who utilize all available resources. (p. 20).

One of the most important companies dedicated to video game localization, Keywords Studio, ${ }^{1}$ based in Ireland, highlights the importance

${ }^{1}$ https://www.keywordsstudios.com/ 
of teamwork and workflow management in order to integrate professionals. Working in the game localization industry, offering art services, engineering, audio services, functionality, localization quality assurance, as well as giving support to game developers and players, the company emphasizes in its website that working across a wide range of projects, from casual and mobile games to AAA titles, ${ }^{2}$ and from batch production to continuous content generation and adaptation, their teams are highly responsive to evolving needs. Delivering culturally adapted content in more than 50 languages, their localization offerings include collaboration between their teams and clients to provide effective localization solutions.

Assuming that localization, for both scholars and the industry, inevitably has levels of collaboration among its agents, forming a collaborative continuum that involves managers, localizers, translators, terminologists, and reviewers or testers, who directly or indirectly influence the text to be translated, teaching video game localization in Translation Programs may also take place through a collaborative pedagogical approach that can dynamically promote the exchange of experiences between translation teachers, students and other collaborators or agents, mirroring the so-called collaborative continuum, and not depriving students of the knowledge about globalized emergent practices and different technologies related to them.

For Kiraly $(1995,2000,2014)$ and González-Davies (2017), adopting a collaborative pedagogy is an effective way to encourage students to engage in critical thinking and problem solving. In addition, such pedagogy promotes a better understanding of the translation process and its results, as well as develops students' attitudinal competence, enabling them to deal with the uncertainties of translations and to make well-informed and responsible decisions in group.

The socio-constructivist thinking, which collaborative classroom experiences are based on, leaves behind the teacher-centered approach and seeks (1) to empower students throughout the production process of a translation with publishing potential; (2) to make students aware of the importance of critical thinking, reflection, interaction among peers, and access to appropriate resources and materials offered by other

\footnotetext{
${ }^{2}$ AAA games are games with high production budgets, usually referring to flagship titles involving substantial resources (O'HAGAN; MANGIRON, 2013).
} 
agents involved in the production of a translation; and (3) to highlight the importance of using authentic materials and activities immersed in real experiences, echoing translation projects similar to those found in professional life, during which unpredictable situations are experienced (KIRALY, 1995, 2000, 2014; GONZÁLEZ-DAVIES, 2017). As claimed by Kiraly (2000),

True collaboration in the classroom does not mean having learners do translations individually in the company of peers. It means sharing responsibility for empowering the entire group as emergent professionals. The process of decisionmaking becomes a second primary focus of attention in the class along with the artifacts of those processes. To ensure true collaboration in the classroom, students must be mutually dependent on each other for accomplishing goals. In their professional lives, as in most human endeavours, translators will have to be able to work co-operatively with each other. Interdependence fosters and teaches responsibility, while individual accountability ensures that each student is contributing to the common goals of the group as well as acquiring the necessary social and translational skills to work professionally upon completing the programme. (p. 67).

For Pitkäsalo and Ketola (2018), in collaborative teaching and learning approaches, students are divided into small groups, and the overall workload is shared among them. The groups coordinate their own duties with one another, guided by the teacher. In other words, the main objectives of this type of collaborative pedagogy, besides developing translation skills in relation to a certain type of text, material, or product, are meant to provide translation students the opportunity to proactively manage translation projects:

The students have to adopt different roles in the translation assignment and coordinate both their own project and time management, as well as those of their respective groups. The execution depends largely on the students taking responsibility and adopting an active role in the process, transcending the traditional classroom setting in which the students merely follow given instructions. (p. 95).

Based on the above, one can affirm that it is possible to turn translation classrooms into a community of practice (WENGER, 1998), 
where students work together and share responsibilities during the learning process. For Wenger (1998), a community of practice is different from a group work, as its members develop their own understanding of how a determined practice can be. This "active" process results in a much richer definition than the simple sequence of goals to be achieved by groups. For the author, a community of practice produces a shared practice, in which its members engage in a collaborative learning process. The term community of practice and its notion is also used and discussed by Kiraly (2000) and González-Davies (2017).

Accordingly, this paper, conceived as a didactic proposal of qualitative and naturalistic bias (GILE, 2009; CHESTERMAN; WILLIAMS, 2002), describes possibilities for incorporating video game localization in Translation Programs using a collaborative pedagogy. Chesterman and Williams (2002) argue that research in Translation Studies needs to investigate the impact of new technologies on translator training. They also emphasize the importance of asking how modules concerning new technologies could include a more detailed study of translation memory systems, localization tools, among others, and how such modules should be worked on with the students during the academic program (CHESTERMAN; WILLIAMS, 2002, p. 26).

Taking into account this methodological delimitation, the main goal of this paper is to describe a sequence of activities that involves students in a collaborative video game localization project, illustrating how some specific tools and materials present in the translation and localization industries can be used to localize an open source video game, as will be explained below.

In addition to this introduction, the following section highlights some reasons why video game localization should be part of the translator education nowadays, especially due to the industry's current statistics and revenues. Section 3 describes the importance of collaborative pedagogy in video game localization teaching, trying to shed some light on the agents that may be part of a collaborative localization project. Finally, the last section envisages that translation teachers and students will probably benefit from this didactic proposal, mainly due to the lack of studies on video game localization teaching through long-lasting, student-centered, and collaborative projects. 


\section{Reasons for incorporating video game localization in Translation Programs: the fast-pace growth of the entertainment market}

There is a general consensus that the first video game ever was created in 1958 by the American physicist William Higinbotham, who made what he later called Tennis for Two, using mostly resistors, capacitors, and relays. Another iconic early title, the classic sports game Pong, released in 1972 by Atari, is also resembled as one of the first games in history.

For Stamenova (2019), however, both Tennis for Two and Pong were the so-called physics games, based on motion and not storyline: "they contained no plot and no characters and therefore required no localization. We would have to wait for the arrival of the 1980s to see gaming localization make its first steps" (STAMENOVA, 2019, p. 41). For the author, the history of game localization begins with Pac-Man. The iconic maze chaser by Namco is probably one of the most legendary and popular game releases of all times. The author explains that it continues ranking among the highestgrossing game titles, and the yellow dot-eating creature is an integral part of pop culture to this very day. Pac-Man is the localized name of the game, since its original title in Japanese roughly transliterates as PuckMan.

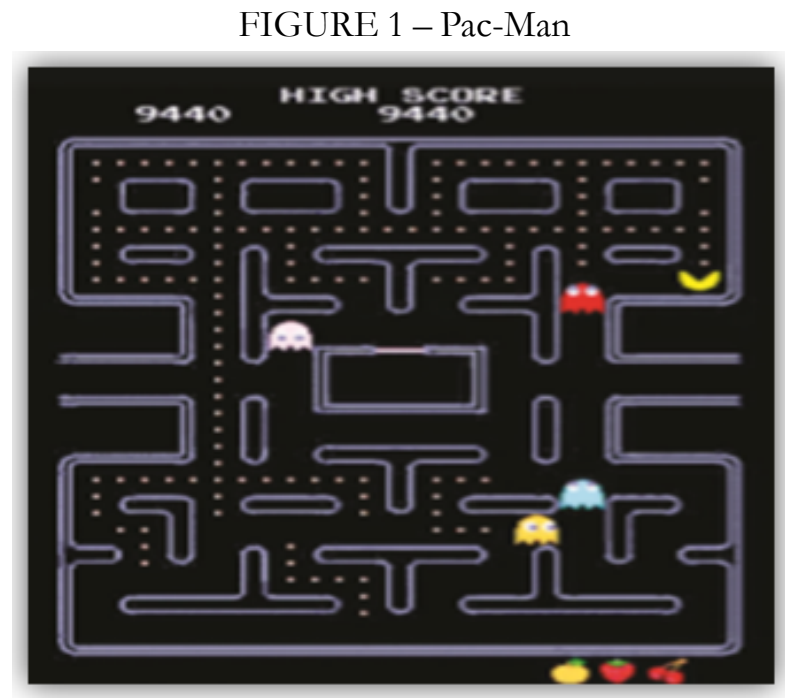

Source: Stamenova (2019).

Stamenova (2019) argues that when exporting the game to the United States, Namco's game developers had some language-related concerns: 
They feared the word "Puck" might be associated with obscene words in English, and therefore changed it to "Pac". What is more, the colorful ghosts in Pac-Man all have names, and those also differ from the originals in Japanese. In order to account for the cultural differences between Japan and the US, the original names Reddie, Pinky, Bluey and Slowly were instead changed to Blinky, Pinky, Inky, and Clyde. (p. 41).

The process of changing the title of the game, as a means through which to account for what the US audience liked and understood, was called localization. For Stamenova, with the lightning-fast development of information technologies, games started becoming more and more complex as well: "text and storyline became essential components of every release and the explosion of global trade meant only one thing: games were no longer a local phenomenon. As such, localization became a necessary requirement" (STAMENOVA, 2019, p. 41).

Since its origin in the $1980 \mathrm{~s}$, game localization has evolved continuously in parallel with the technological advances of the gaming industry (O'HAGAN; MANGIRON, 2013; MANGIRON, 2018). The first Japanese video games contained small quantities of texts, whereas today they are technologically sophisticated, merging different assets in just one product, such as in-game text (menus, help messages, tutorials), scripts, graphics, and other associated materials, such as box and docs (including user manual), requiring specific localization and translation in order to be commercialized in different countries.

Mangiron (2018) states that video games have become a worldwide phenomenon and one of the main leisure options in the modern digital society. For the author:

The success of the game industry can be attributed, to a large extent, to GILT (Globalisation, Internationalisation, Localisation and Translation) practices, which have made video games available in every corner of the world by customising them to suit the target territory preferences and localising them into the players' languages. The ultimate goal of game localisation is to provide players of the localised versions with an engaging and immersive gameplay experience that is similar to that of the original players. (p. 277). 
Mangiron (2018) also argues that video games are often highly customized to meet target players' preferences and expectations, generating billionaire budgets and revenues.

According to Tom Wijman (2019), Senior Games Market Analyst at NewZoo, ${ }^{3}$ in 2018 , as regards game revenues, the top 25 public companies generated a combined $\$ 107.3$ billion dollars, a $16 \%$ increase when compared to 2017. For the analyst, this marks the first time they have exceeded the 100-billion-dollar mark - a major milestone for the market. Together, these companies accounted for almost $80 \%$ of the $\$ 134.9$ billion global games market.

Wijman (2019) also explains that the Chinese multinational company Tencent alone earned $\$ 19.7$ billion dollars in revenues, accounting for almost $15 \%$ of the entire games market, and was the world's first public company in game revenues for the sixth year running, followed by Sony, Microsoft, Apple, Google, and Activision Blizzard, respectively. In the case of the companies Apple and Google, Wijman (2019) also points out that:

Apple and Google have always fared well on our top 25 public companies ranking. The American tech giants' consistently strong performance is a direct result of revenues generated by their respective app stores, where both take their cut of every transaction. Both companies recently revealed new initiatives that will expand their involvement in the global games market. (paragraph 4).

While Google recently launched Stadia, its cloud gaming platform that allows users to stream entire games via the Internet, Apple released Apple Arcade, both in 2019. The subscription service gives users access to a library of 100 new games for a monthly subscription fee.

Concerning platforms, Wijman (2019) estimates that even though console games showed a particular growth in 2018, accounting for $38 \%$ of revenues earned by the top 25 companies, up from 34\% in 2017, including the three main holders Sony, Nintendo, and Microsoft, the mobile gaming platform still holds the first place in generating revenues. In Wijman's words:

\footnotetext{
${ }^{3}$ https://newzoo.com/insights/articles/top-25-public-game-companies-earned-morethan-100-billion-in-2018/
} 
Under the pressure of a dynamic market, continuously changing business models, and high consumer expectations, traditionally large console publishers, such as Activision Blizzard, EA, and Ubisoft, have struggled to keep pace with the growth of the platform holders. (paragraph 13).

Beyond the role of advancing the art of human narrative, games as an economic powerhouse is another key piece of evidence as to how they have quickly become an integral part of our culture. Within the industry, it is a common fact that games make more money than film and music combined. In 2017, it was estimated that 2.2 billion people around the globe were gamers and, in that year, global video game revenues easily surpassed $\$ 100$ billion dollars. By comparison, global film revenues were $\$ 40.6$ billion that year, while global music was $\$ 17.3$ billion. What is even more staggering is that if one takes the global live sports market and combines them all (FIFA, NFL, MLB), in 2017 their total revenues of $\$ 90.9$ billion still falls short of that received for video games. In Edwards' words:

We are seeing games influencing mainstream culture more and more, and this is continued evidence of the broader role they play. Sports stars and movie stars often reference games like Fortnite (for example) and are open about the positive role games play. (EDWARDS, 2019, p. 19).

In the case of Brazil, Macedo and Vieira (2017, p. 154) claim that 66.3 million Brazilians play some type of video game, including from the simplest versions available in browsers and smartphones, to the more sophisticated options, designed for consoles and computers. Basing their research on Game Brasil 2017, a survey conducted by Brazilian companies, such as Sioux, Blend New Research, and Escola Superior de Propaganda e Marketing (ESPM - Propaganda and Marketing Higher Education Institute), Macedo and Vieira (2017) state that the game market in Brazil generated a revenue of $\$ 1.3$ billion dollars in 2017 , ranking the country as a leader in the number of gamers in South America, and the $13^{\text {th }}$ place in the world.

According to Gilboa (2019, p. 48), one surprising prediction is that Brazilian Portuguese is growing as it becomes the world's $13^{\text {th }}$ biggest gaming market. Brazil is also the fifth largest population in the world with more than 66 million gamers. In the author's opinion, this rise has clearly been noticed by key actors of the gaming industry, such as Sony, Ubisoft or Activision, and big things are going to happen over the next few years. 
Calling game localization as a culturalization phenomenon, Pérez and Sáenz (2019) explain that:

Over the past years, we have worked hard in localization to make sure that players get to live the full game experience adapted to their culture and the aspects that surround them. We have gone to great lengths to make sure that localized versions of video games are culturally correct; we have even coined a term: culturalization. And this amazing achievement has come to a reality as we strive to attain the best localization possible, one in which players don't realize that they are not playing the original version of the game. (p. 32).

Based on the above, one can affirm that from the perspective of Translation Studies, the proliferation of video games can only have a positive impact on the area. The more one creates games and platforms, the more one needs to translate and localize them.

As stated in the Introduction of this paper, this section intended to show that the current pace of change in consumer behavior, media, technologies, and the statistics revealing high revenues on game industry requires a new type of translator that is aware of localization practices, giving Translation Programs good reasons to include them in their curricula, for both research and professional purposes (O'HAGAN; MANGIRON, 2013). This can make it possible for students to both study the topic and be able to search for new translation and localization job opportunities in a fast-paced and growing game market.

\section{Training translators in video game localization through a collaborative pedagogy}

\subsection{General description of the activity}

One way of enhancing the students' learning experience is by arranging students in small groups, assigning them tasks to collaborate in a localization project, and complementing each other's skills within the team. Depending on the size of the project, teachers and students can set up different company-like groups and assign them roles. Students' roles should rotate among the various members of the team so that all students 
can be aware of different tasks, pressures, and responsibilities involved in the process. As previously noted, collaborative approaches are also found in the localization industry.

Whether localizing a game for one locale or different locales, hiring in-house game experts or outsourcing translation agencies, the video game industry needs a variety of professionals in order to guarantee the satisfaction of international markets. The following is a brief description, adapted from Bernal-Merino (2008, 2015), of the main professionals usually searched for by game developing companies:

- Localization managers: these people are normally the point of contact for publishers and ultimately responsible for obtaining all the original linguistic assets, and delivering the translations fully tested. Managers need to liaise with the localization coordinators to make sure that the language register is correctly pitched, as well as compliant with each platform's branding and naming conventions. Chandler and Deming (2012, see chapter 5) devote an entire chapter to the role of localization managers, which is very important for every member involved in the localization process, and particularly for translators and linguistic testers. However, the authors explain that, in the real world, the amount of information they usually provide is normally not enough because translators may only receive text files to be translated in an Excel spreadsheet, therefore lacking the whole localization kit, which includes the game and its context information;

- Translators (in-house, freelancers): these people are responsible for the bulk of the translation process at the beginning of the project. Translators are expected to work with translation memory systems, word processors, tables, and spreadsheets. The variety of formats and lack of context can make the translator's task unnecessarily complex;

- Localization coordinators: these people are indirect contacts with all the translators and outsourced companies handling the translation, as well as with the heading linguistic testers. These professionals are responsible for making sure that all language versions go smoothly and on target. Coordinators have to verify that 'bug reports' are being filled in accurately, and that relevant information is being shared among all testers, as well as check that engineers understand the corrections detailed in the report; 
- Head linguistic testers: these people are in charge of overseeing the linguistic proofing, and overall quality of the languages being tested, as well as the implementation of bug reports that will in turn be passed on to engineers who have to make the corrections in the game code; and

- Linguistic testers: these people must meticulously explore every text, option, dialog, and menu of the game, and verify that the language used is terminologically accurate, correctly written, and in line with the feel of the original game.

Once featured in the game industry, these roles can be pedagogically assigned to translation students. It is assumed that an entire class of approximately 20 students is involved in the completion of the game localization project.

The activity can firstly be performed by separating the main roles among students. The teacher may, during the course of the project, act as a facilitator, solving doubts or suggesting more satisfactory translations for certain terms of specialty, but it is the students' responsibility to coordinate their learning process. It is suggested that students work collaboratively in small learning groups, composed of three or four students to fulfill the different phases of the project. With the guidance of the teacher, the class can choose localization managers who will organize, moderate and streamline the efforts of students-translators, students-localizers and student-testers. After deciding which game (see section 3.2) will be localized:

1) students-managers will be responsible for downloading the localization kit of the game (containing all the source files to be translated) together with some background documentation, and provide them to translators followed by a list of priorities, and clear deadlines;

2) students-translators will be assigned to translate the linguistic assets (or resources) of the game, using a translation memory system. This group can be composed by four to five students, depending on the classroom setting;

3) students playing the role of localization coordinators must verify if there is any relevant information contained in the files produced by translators through the translation memory system, which will later be shared among testers, or even comments or reports; localization coordinators will check the game terminology as well, considering the genre of the game; 
4) students acting as head linguistic testers can revise the translation and overall quality of the language being tested. This phase is similar to proofreading and must be done by a team of students-testers to guarantee consistency;

5) students-testers will explore every text, option, and menu of the game, and verify that the language used is terminologically accurate, correctly written, and in line with the feel of the original game. They will also play the game. Linguistic testing is a very important part of the localization process, because it is the first time the video game can be seen and played with the translation. Testers have to play every single option in the game from beginning to end in order to spot misspellings, mistranslations, and any other type of mistake. They cannot correct anything themselves and can only describe the error through a "bug report" (written in a simple txt file) for the students-translators to correct before publishing.

As already mentioned, the roles played by the students can alternate in a subsequent project, so that all students can experience the various phases of preparing a game localization. It is recommended that a collaborative project only be implemented in the translation teaching classrooms after students are already familiar with the basic functionalities of a translation memory system, have basic knowledge about terminology, and are familiar with fundamental readings on the interplay between translation and localization. Thus, an authentic and collaborative translation project involving game localization can make up an advanced module related to translation technologies, providing students with knowledge regarding the manipulation of other functionalities of the systems. It is also advisable that the game to be translated in this type of module has a low linguistic density so that the team will be able to accomplish its localization project.

Regarding the types of localization, another important point is to adopt a partial localization in translation classrooms, since probably few students will have the necessary knowledge on computer languages to change graphics and other technical functionalities of the game.

The game market and the truly multinational scope of multimedia products in the $21^{\text {st }}$ century require, among other things, a legion of language and localization experts working collaboratively to help companies not only sell their products abroad, but also establish their brands beyond their national borders. As a result, more people than ever are nowadays seeking to become professional translators. However, the range of translation services 
has wildly increased in number and in variety, and some of the services are significantly different from those offered just ten or fifteen years ago. This fast pace has led many translators to learn new skills on the job, because it was too early for new training. Video game localization represents a prime example of this fairly new and highly technical expertise. This is why incorporating a module of game localization in Translation Programs can shorten the path for modern-day students and future translators.

\subsection{Choosing the game}

Teachers and students can decide on the game to be translated, or, in an even more ideal situation, they may receive a request from a national or international game developer. Nevertheless, due to the difficulties of achieving partnerships with game developers, who fear information leakage and piracy, free and open source materials available on the Internet can be one of the best options for academic institutions, which indeed can avoid problems with copyright laws.

Teachers and students can access Internet trending repositories to search for free games that were not yet translated into Brazilian Portuguese, such as GitHub. In general terms, GitHub is a repository on the Internet that freely distributes the source code of several developer companies and aspiring developers. Linked to the open source initiative, it is estimated that 40 million developers share their projects on this network, available at https://github.com/, forming more than 55 million repositories.

To illustrate this, the game chosen as an example in this paper is the free open source game Out Run-Style JavaScript-Racer. This game was inspired by Out Run, which is an arcade game released by Sega in September 1986. Out Run is known for its pioneering hardware, graphics, and innovative features such as nonlinear gameplay and a selectable soundtrack with music composed by Hiroshi Kawaguchi. Designed as a racing game where the goal is to avoid traffic and reach one of five destinations, Out Run (Figure 2) was set up for players to enjoy the experience of driving. 
FIGURE 2 - The sit-down deluxe cabinet version of Out Run equipped with a steering wheel, a stick shift, and acceleration and brake pedals

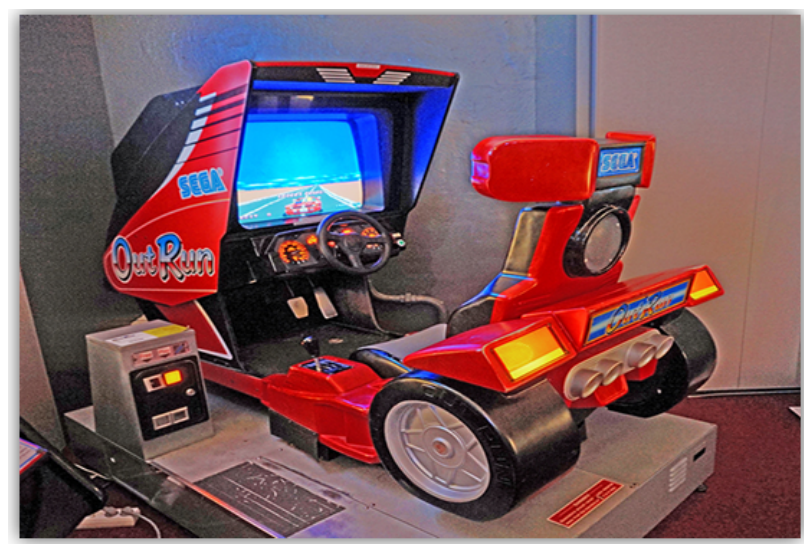

Source: https://en.wikipedia.org/wiki/Out_Run.

As in the original Out Run, the Out Run-Style JavaScript-Racer is a racing game for computers whose goal is to avoid traffic and reach destinations, where players can enjoy the experience of driving by choosing one of the four destinations, which encompass straight, curve, hill and final lanes with heavy car traffic (Figure 3).

FIGURE 3 - Start menu of the game JavaScript-Racer opened in a browser

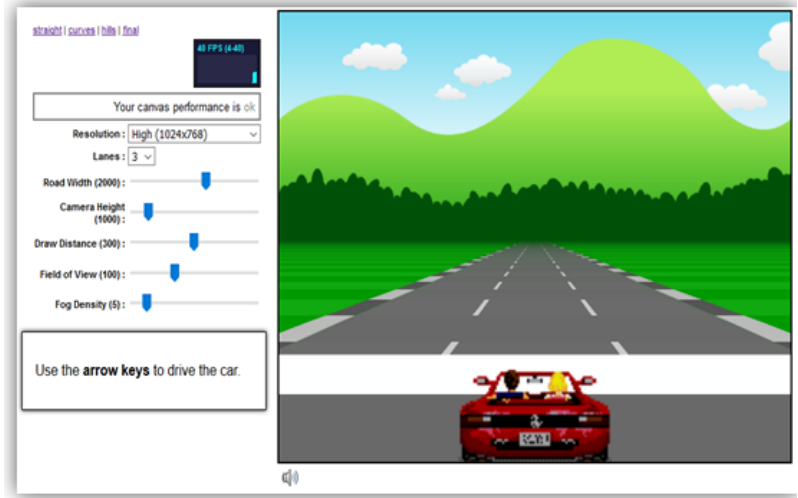

Source: JavaScript-Racer. 
It is worth highlighting that besides GitHub, in the annual open-source yearbook at Opensource.com, ${ }^{4}$ teachers and students can also investigate a list of open source software, including video games and other sorts of games with their respective files, equally allowing their use for didactic and pedagogical purposes (see ESQUEDA et al., 2018).

\subsection{Collaboratively localizing the game JavaScript-Racer ${ }^{5}$}

Access to the game through the GitHub website can be done by typing in Google bar: github javascript-racer or https://github.com/jakesgordon/ javascript-racer. When reaching the website, students-managers will find the following information regarding the package of the game, as shown in Figure 4:

FIGURE 4 - GitHub website containing information on JavaScript-Racer

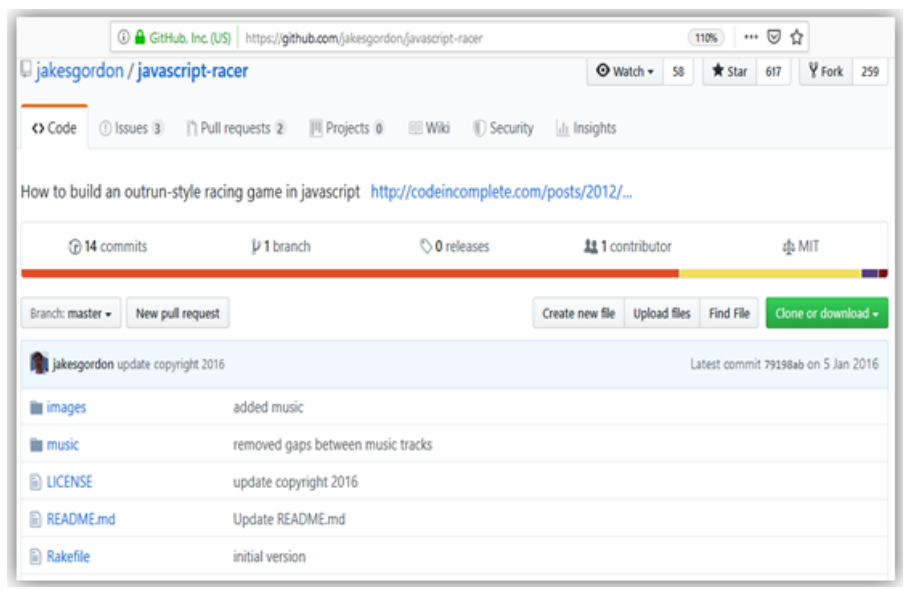

Source: https://github.com/ jakesgordon/javascript-racer.

\footnotetext{
${ }^{4}$ https://opensource.com/yearbook/2018

${ }^{5}$ Jakes Gordon recommends that the performance of this game is very machine/browser dependent. It works quite well in modern browsers, especially those with GPU canvas acceleration, but a bad graphics driver can kill it stone dead. So its mileage may vary. Gordon advises that there are controls provided to change the rendering resolution, and the draw distance to scale to fit the user's machine. Currently supported browsers include: Firefox (v12+) works great, 60fps at high resolution; Chrome (v19+) works great, 60fps at high resolution; IE9- ok, 30fps at medium resolution (it is not that great, but it works).
} 
A folder with several files of the game can then be downloaded through the tab "Clone or download", at the upright side of the page. All files, after being saved, can be named localization kit (Figure 5). To run the original game on the computer and to check if everything is running properly, students-managers will access the folder, search for the index file and open it in a browser (as shown in Figure 3 above). Through this action, they can also have an idea of the linguistic density of the game, thus enabling the planning of the project. The developer of the game, Jakes Gordon, has freely provided in the repository the source code of the game in HTML, and files with html extension can be easily opened in translation memory systems.

FIGURE 5 - The directory containing the game files

\begin{tabular}{|c|c|c|c|c|}
\hline \multirow{2}{*}{ Acesso rápido } & Nome & Data de modificaş... & Tipo & Tamanho \\
\hline & images & $14 / 08 / 201813: 05$ & Pasta de arquivos & \\
\hline a OneDrive & $\square$ music & $14 / 08 / 201813: 05$ & Pasta de arquivos & \\
\hline \multirow{2}{*}{$\square$ Este Computador } & ie) common & 05/01/2016 03:51 & Documento de fol... & $3 \mathrm{~KB}$ \\
\hline & S common & 05/01/2016 03:51 & Arquivo JavaScript & $18 \mathrm{~KB}$ \\
\hline Área de Trabalho & Dinder & 05/01/2016 03:51 & Firefox HTML Doc... & $1 \mathrm{~KB}$ \\
\hline \multirow{2}{*}{$\begin{array}{l}\text { Documentos } \\
\checkmark \text { Downloads }\end{array}$} & LICENSE & 05/01/2016 03:51 & Arquivo & $2 \mathrm{~KB}$ \\
\hline & Rakefile & 05/01/2016 03:51 & Arquivo & $2 \mathrm{~KB}$ \\
\hline \multirow{6}{*}{$\begin{array}{l}\text { Imagens } \\
\text { Músicas } \\
\text { Objetos 3D } \\
\text { Dideos } \\
\text { Disco Local (C:) }\end{array}$} & D README.md & 05/01/2016 03:51 & Arquivo MD & $5 \mathrm{~KB}$ \\
\hline & [S] stats & 05/01/2016 03:51 & Arquivo JavaScript & $4 \mathrm{~KB}$ \\
\hline & D v1straight & 05/01/2016 03:51 & Firefox HTML Doc... & $15 \mathrm{~KB}$ \\
\hline & D v2.curves & 05/01/2016 03:51 & Firefox HTML Doc... & $18 \mathrm{~KB}$ \\
\hline & D v3.hills & 05/01/2016 03:51 & Firefox HTML Doc... & $20 \mathrm{~KB}$ \\
\hline & D vifinal & 05/01/2016 03:51 & Firefox HTML Doc... & $31 \mathrm{~KB}$ \\
\hline
\end{tabular}

Source: the author.

To be able to manipulate the linguistic content of the game and to translate it into Portuguese, students-translators, after receiving the localization kit from the students-managers, need to open the index file in a translation memory system.

Translation memory systems currently constitute essential work tools for translators providing services in various fields of specialization, mainly due to their capability of storing large amounts of bilingual data and fast retrieving excerpts of previous translations that systems consider to be a full or fuzzy (partial) match to the translation in hand. For these systems to work effectively and promote greater consistency, the terminological and phraseological translation options stored in the systems' database must be recycled into the new translated text. As these systems recover previously translated segments, translators are able to save time by reusing complete segments of past translations (in full-match cases) or editing pre-translated 
portions of text to fit them into a new or updated (con)text (in fuzzy matches) (ESQUEDA et al., 2016).

Although several free and open source translation memory systems, such as Potext, Drupal, or Virtaal, can perform the action of opening HTML files, in this proposal, the Wordfast Anywhere software will be used as an example. Being a free translation memory system, Wordfast Anywhere ${ }^{6}$ allows for the maintenance of the workflow of the localization process by retaining the original and translated files in a database for future updates or changes, keeping the original graphics and layout of the files, besides making it possible to share the data of the project among different studentscollaborators to meet the collaborative pedagogical approach purpose. Figure 6 shows the linguistic strings of the main menu of the game opened in the translation memory system, Wordfast Anywhere.

FIGURE 6 - The index file with the linguistic assets of the game opened in the translation memory system, Wordfast Anywhere

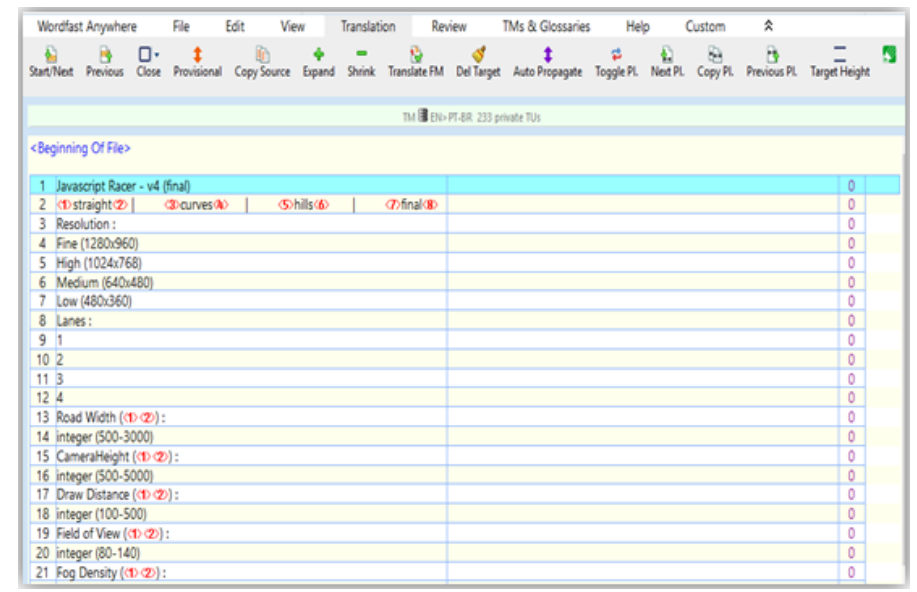

Source: The author.

The Wordfast Anywhere system extracts only the linguistic content from the game. As one can see in Figure 6, in the software interface, the left column shows the original text, and the right column shows the boxes for inserting its corresponding translations. Once texts are segmented, finding context for strings can also be quite difficult. That is why students-translators must receive the localization kit with all files from students-managers in

${ }^{6}$ https:/ / freetm.com 
order to produce specific visual references to help them understand the game. The localization kit and the first instructions from students-managers are a very valuable source of information. They might, for example, clarify what a single word like "resolution" (line 3 in Figure 6) refers to and into which grammatical form it should be translated.

While preparing their translations, students-translators can download an unfinished version of the translation from the translation memory system, save it equally in HTML, and paste it in the same localization kit folder. This step allows students to check and simulate if the translated words and phrases have not exceeded the limits of the screen or the space designed for the original sentence.

Calek (2019, p. 20) remarks that "character limitations are probably the first technical aspect that comes to mind when localizing a game. It is often a challenge to find a working compromise between style and character limitation."

Figures 7 and 8 illustrate that the line "Use the arrow keys to drive the car" was translated into Brazilian Portuguese Use as setas do teclado para dirigir o carro, without any damage to the game graphics and layout.

FIGURE 7 - Original sentence "Use the arrow keys to drive the car" (line 23) opened and translated into Brazilian Portuguese in the translation memory system, Wordfast Anywhere

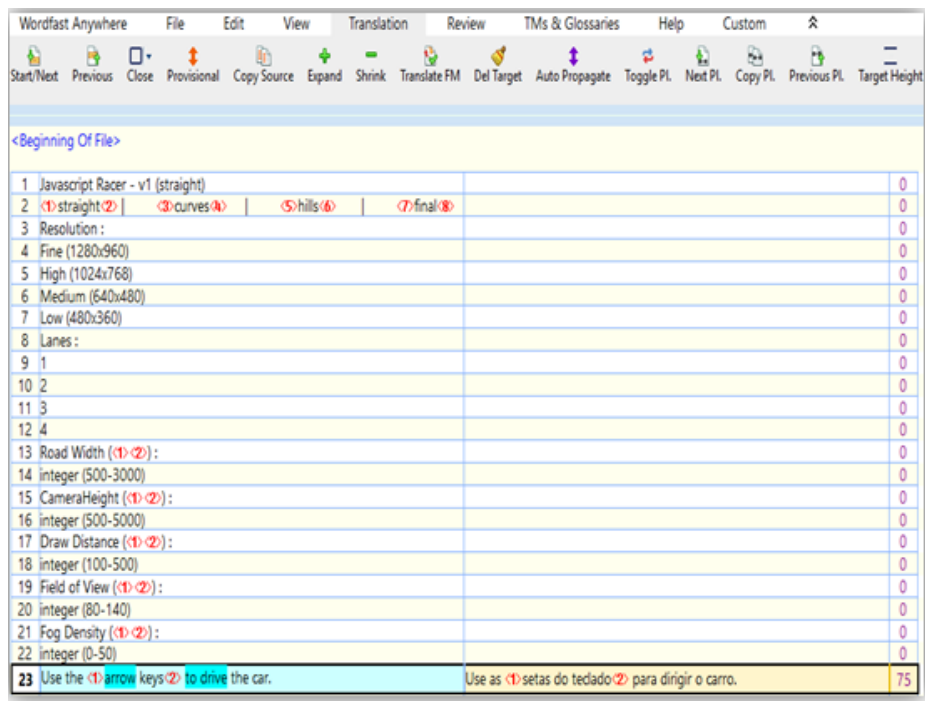

Source: the author. 
FIGURE 8 - Translated sentence Use as setas do teclado para dirigir o carro opened through the browser to check its length in the game

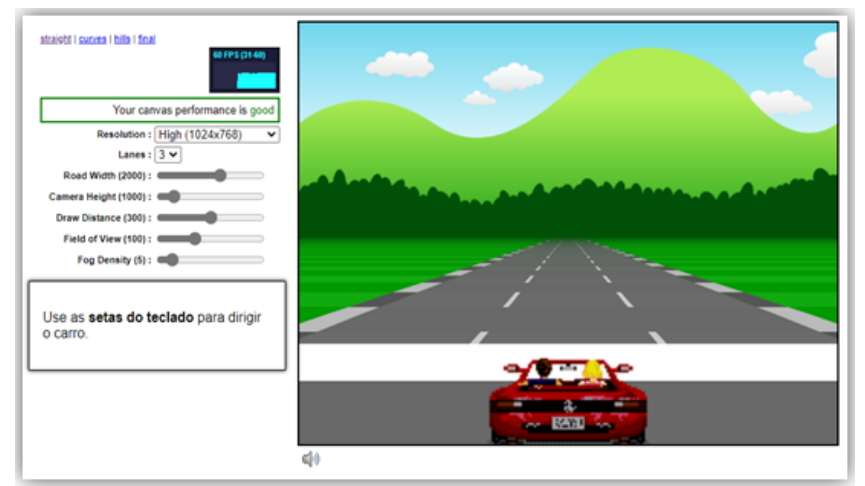

Source: the author.

According to Stamenova (2019), one of the many peculiarities that sets game text apart lies within the very nature of games. A game is, at its core, a program. As such, the text it contains cannot be defined as pages or texts, but as strings. These strings need to be appropriated into the program's visual representation in the user interface (UI). In games, just like in other types of software, there is limited space available for each string, so one cannot afford to be lengthy. Exceeding the string's length limits often results in text bleeding out of its allocated space, which is detrimental to the UI's esthetics, can create issues with other strings, and can even render the string unreadable. Giving some examples of the problem related to space restrictions, Stamenova (2019) explains that:

In the past, length limits used to be a massive issue in game localization. This was because there was no precise way to measure how much space the localizer really had. American video game producer and translator of Final Fantasy VI Ted Woolsey recounts that he had to review and cut his English translations multiple times so that they properly fit into the game's layout: "Look at those tiny menu boxes! You can't fit 'Attack with your weapon, dealing physical damage' in there, but "Attack" is clear enough on its own". Luckily, length limits are somewhat easier to manage these days. (p. 42-43).

It is thanks to technological advancements around the 2000s that strings were allowed to be stored in the ASCII format and not as images, and to the rise of computer-assisted translation software, like translation 
memory systems, that sentences and words can be rewritten to adjust specific length limits for each string. Professionals as well as students-managers, students-translators, and students-testers still have obviously to keep limits in mind, but they do not have to rely on guesswork, since they have the localization kit and the database, and may collaborate through a translation memory system, editing strings as many times as they wish before publishing the game.

After translating all the linguistic strings of the game, studentstranslators can visualize them on the browser, as shown in Figures 9 and 10, and send the translated files to the students-coordinators.

FIGURE 9 - Original start menu of the game

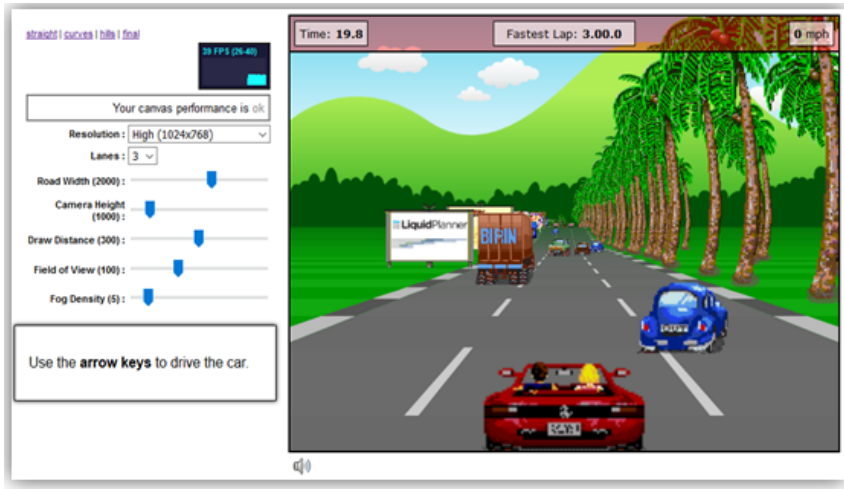

Source: JavaScript-Racer

FIGURE 10 - Partial translation of the original start menu of the game into Brazilian Portuguese

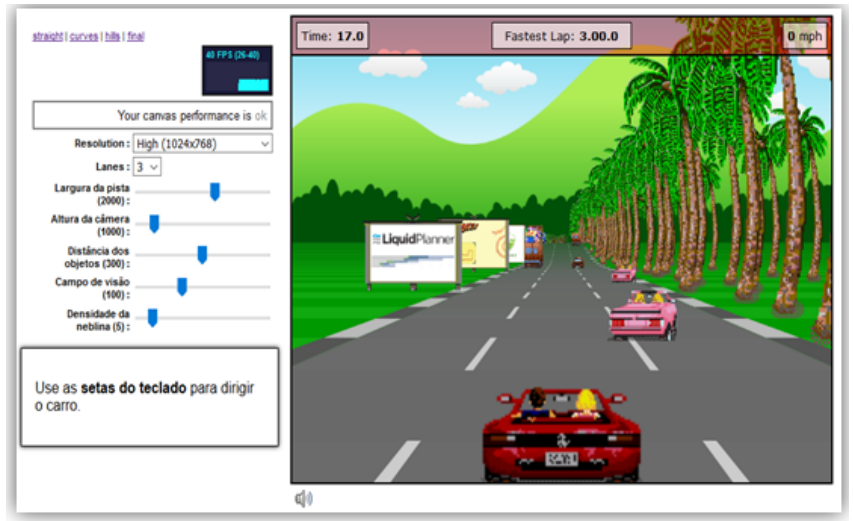

Source: the author. 
Students playing the role of localization coordinators must verify if there is any relevant information contained in the files produced by studentstranslators in the translation memory system, Wordfast Anywhere. It is important to keep the entire project consistent and to use the same style and wording for different characters and user interface portions. Effective communication and a well-maintained terminology database help achieve consistency. Due to the fact that each game has different requirements, this process of constant adjustment and adaptation needs to be double checked in relation to the game genre, in this case, a racing game.

Acting as head linguistic testers, the next group of students will revise the translation and overall quality of the language being tested through the files produced by the students-translators in the translation memory system and already checked by the students-coordinators. As pointed out earlier, this phase is similar to proofreading and it has to be done by the group of students-testers to guarantee consistency. Being a cloud translation memory system, one of Wordfast Anywhere's greatest features is its memory and glossary sharing functionality, which allows translators to share work and have access to each other's translations in real time. For teamwork to be possible, it is necessary to select the memory or glossary to be shared and click on the Share option, which opens a window to configure the studentsrevisers' emails with which the memory or glossary will be shared (Figure 11). Sharing can occur with more than one student, who may have different types of memory access in common as "guests" with read only or replacing (or overwrite translation unit) permissions.

When sharing the translations options, teachers and students may discuss that video games are no longer a niche hobby for nerds. Nowadays, video games are worth billions of dollars, as we have seen in section 2 . However, apart from the financial side of the games, in terms of creation value, students can produce some astonishing results and can be encouraged to go beyond their duty and create true masterpieces, comparable or even better than the original. 
FIGURE 11 - Share options for translation memory exchanges in Wordfast Anywhere

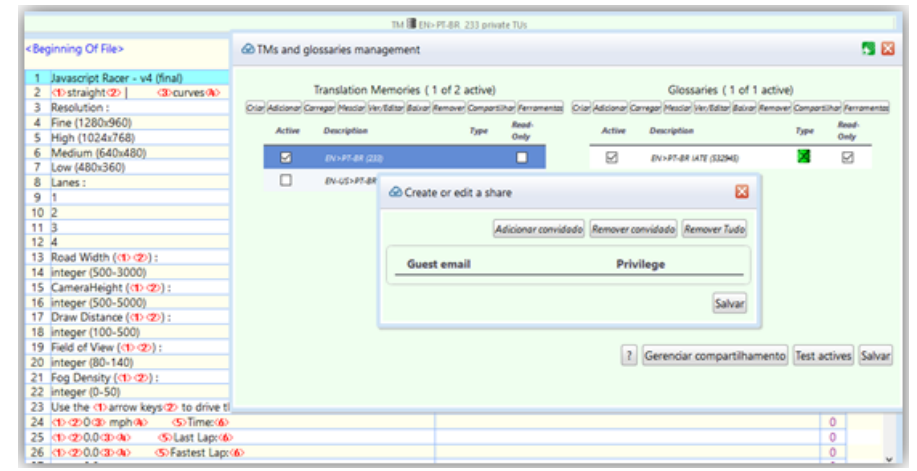

Source: the author.

After all the strings for improvement have been collaboratively identified, the translated game should be sent to students-testers.

Translating it is not the same as playing a game. Students-translators were worried about single strings, often not in the order they would appear in-game, but sorted alphabetically by their strings in the translation memory system interface.

In this last phase, students-testers will explore every text, option, and menu of the game, and verify that the language used is terminologically accurate, correctly written and in line with the feel of the original game. They will also play the game. As discussed by Bernal-Merino (2008), linguistic testing is a very important part of the localization process, as it is the first time the video game can be seen and played with its translation. Testers must play every single option in the game from beginning to end in order to spot any type of mistake, reporting it in a form of "bug report" for the students-translators to correct problems before publishing.

After all adjustments, the game will be returned to students-managers, who will proceed to its publication. They may create a team account in the repository GitHub where they will host JavaScript-Racer translated into Brazilian Portuguese. They can also create a "read me" file in order to present the localization project and its members, and use their creativity to launch their product to both old and new fans of racing games.

A collaborative academic training would give students a head start in the professional arena while at the same time catering to the globalized video 
game localization market. Together with theoretical readings, discussions among peers, and awareness of concepts, definitions, and the metalanguage used on the field, students can boost the quality of their linguistic transfer.

\section{Final remarks on the benefits of a collaborative pedagogy in video game localization}

Given that video game localization inevitably has levels of collaboration among their agents, forming a collaborative continuum that involves localization managers, translators, localization coordinators, and testers, who directly or indirectly influence the game to be localized, game localization teaching in Translation Programs can also adopt a collaborative approach, dynamically promoting experience exchanges between teachers, students, and other collaborators. Conceived as a didactic proposal of qualitative and naturalistic bias (GILE, 2009; CHESTERMAN; WILLIAMS, 2002), this paper sought to describe the possibilities for incorporating video game localization in translation teaching using a collaborative pedagogy (KIRALY, 2000).

Following a sequence, collaborative activities herein illustrated begin with the assignment of teachers' and students' roles, the choice for a free and open source game to be localized, the handling of a translation memory system to achieve collaboration purposes among students, the final revision of the game, and its publication in a free repository on the Internet.

Instead of seeking to present only theoretical texts on the interplay between translation and global market involving games, using a conventional and transmissionist teaching method (see ESQUEDA, 2018; 2020), teachers may adopt a collaborative pedagogy for game localization teaching, providing knowledge sharing, action, and reflexive and critical thinking when it comes to solving translation and localization problems. For Kiraly (2000), since the most valuable learning experiences are the authentic experiences, it is essential to contextualize learning:

Simply providing an imaginary assignment will surely have some, albeit very limited, impact on the authenticity of the situation. If used in a conventional, teacher-oriented class, the didactic assignment would be invented by the teacher, and the students' translations would still be judged for accuracy and acceptability against the arbitrary yardstick of each teacher's 
idiosyncratic criteria. There will still be no real translation situation and no feedback from the real world outside of the classroom. And it is precisely this link to the real world that I feel is the key to an adequately authentic translation situation. (p. 66).

Through collaborative pedagogy, the school environment is conceived as a social, human, and dialogical context like any other (GONZÁLEZDAVIES, 2017), enabling students to act as professionals who effectively interact with other agents involved in the translation process.

With regard to the translation of the game itself, it can be said that translating a low number of linguistic strings, with no terminological complexity, as is the case of the JavaScript-Racer game described herein, may seem technically easier than localizing an utilitarian software, because translators do not need to translate multiple file types, nor compile and test them all in the target language. However, the translation of a game can be cognitively more complex because, in addition to reading and understanding texts without context or segmented texts, it also requires the team of students to "coordinate creativity", as claimed by Calek (2019) and highlighted in the Introduction of this paper. In localization projects students will agree on which translations would best correspond to the start menu of racing games, which translation would be more suitable for the spaces dedicated to a determined string, what is the common language used by fans of racing games, among others. Additionally, teachers and students will discuss the effects of handling different kinds of files and tools designed for localization and collaboration in translation as well.

Finally, it is worth noting that this didactic proposal lacks application in a real teaching environment in Translation Programs, prospecting the implementation of a qualitative-experimental research (GILE, 2009), mainly with the purpose of examining within students whether they understand that a community of practice (WENGER, 1998; KIRALY, 2000; GONZÁLEZDAVIES, 2017) is different from a group that has common interests, but is rather defined as a collaborative production of knowledge. 


\section{References}

BERNAL-MERINO, M. Á. Translation and Localisation in Video Games: Making Entertainment Software Global. New York; London: Routledge, 2015. DOI: https://doi.org/10.4324/9781315752334

BERNAL-MERINO, M. Á. Training Translators for the Video Game Industry. In: DÍAZ CINTAS, J. (ed.). Didactics of Audiovisual Translation. Amsterdam; Philadelphia: John Benjamins Publishing Company, 2008. p. 141-155. DOI: https://doi.org/10.1075/btl.77.14ber

CALEK, S. What's in a Game Translator? Multilingual, Sandpoint, ID, v. 30, n. 3, p. 19-22, 2019.

CHANDLER, H. M.; DEMING, S. O. M. The Game Localization Handbook. 2. ed. Sudbury; Mississauga; London: Jones \& Bartlett Publishers, 2012.

CHESTERMAN, A.; WILLIAMS, J. The Map: A Beginner's Guide to Doing Research in Translation Studies. London: Routledge, 2002.

DUNNE, K. Localization. In: SIN-WAI, C. (ed.). The Routledge Encyclopedia of Translation Technology. London: Routledge, 2015. p. 550-562.

EDWARDS, K. The Future of Video Game Content. Multilingual, Sandpoint, ID, v. 30, n. 3, p. 18-19, 2019.

ESQUEDA, M. D. Ensino de tradução: abordagens pedagógicas de professores brasileiros e canadenses. Revista Belas Infiéis, Brasilia, v. 9, n. 1, p. 127-166, 2020. DOI: https://doi.org/10.26512/belasinfieis.v9.n1.2020.24657. Available at: https:// periodicos.unb.br/index.php/belasinfieis/article/view/24657/. Retrieved on: Aug. 13, 2020.

ESQUEDA, M. D. Ensino de tradução: culturas pedagógicas. Trabalhos em Linguística Aplicada, Campinas, v. 57, n. 2, p. 1244-1273, 2018. DOI: http://dx.doi.org/1 0.1590/010318138651880364601. Available at: https://www.scielo.br/scielo. php?pid=S0103-18132018000201244\&script=sci_arttext\&tlng=pt. Retrieved on: Aug. 13, 2020.

ESQUEDA, M. D. et al. Teaching Video Game Translation: First Steps, Systems and Hands-on Experience. Texto Livre, Belo Horizonte, v. 11, n. 1, p. 103-120, 2018. DOI: https://doi.org/10.17851/1983-3652.11.1.103-120. Available at: https:// periodicos.ufmg.br/index.php/textolivre/article/view/16783. Retrieved on: Aug. 13, 2020. 
ESQUEDA, M. D. et al. A Critical Approach Proposal for Training Translation Memory Systems in Translator Education Programs. Forum - Revue Internationale d'Interprétation et de Traduction / International Journal of Interpretation and Translation, [S.l.], v. 14, n. 1, p. 78-98, 2016. DOI: https://doi.org/10.1075/forum.14.1.05dea.

GILBOA, A. Emerging Trends and Developments in Game Localization. Multilingual, Sandpoint, ID, v. 30, n. 3, p. 32-35, 2019. DOI: https://doi. org $/ 10.1002 / \mathrm{msid} .1036$

GILE, D. Basic Concepts and Models for Interpreter and Translator Training. Amsterdam; Philadelphia: John Benjamins Publishing, 2009. DOI: https://doi.org/10.1075/ btl.8

GONZÁLEZ-DAVIES, M. A. Collaborative Pedagogy for Translation. In: VENUTI, L. (ed.). Teaching Translation: Programs, Courses, Pedagogies. New York: Routledge, 2017. p. 71-78. DOI: https://doi.org/10.4324/9781315623139-9

JELAČA, J. Localization Maturity in Game Development. Multilingual, Sandpoint, ID, v. 30, n. 3, p. 26-28, 2019.

KIRALY, D. From Assumptions about Knowing and Learning to Praxis in Translator Education. InTRAlinea, Bologna, Special Issue: Challenges in Translation Pedagogy, p. 1-9, 2014. Available at: http://www.intralinea.org/print/article/2100. Retrieved on: Oct. 02, 2019.

KIRALY, D. A Social Constructivist Approach to Translator Education. Empowerment from Theory to Practice. Manchester: St. Jerome, 2000.

KIRALY, D. Pathways to Translation: Pedagogy and Process. Kent, OH: Kent State University Press, 1995.

MACEDO, T.; VIEIRA, M. C. Beyond the Pixels: Consumption and Material Culture Experiences in League of Legends. CMC Comunicação, Mídia e Consumo, São Paulo, v. 14, n. 41, p. 146-169, Sep./Dec. 2017. DOI: https://doi.org/10.18568/ cmc.v14i41.1386. Available at: https://search.proquest.com/openview/87a5ee3 9cb54df4c27fd426007936369/1 ?pq-origsite $=$ gscholar\&cbl=2046361. Retrieved on: Aug. 14, 2020.

MANGIRON, C. Reception Studies in Game Localization. In: GIOVANNI, E. G.; GAMBIER, Y. (ed.). Reception Studies and Audiovisual Translation. Amsterdam; Philadelphia: John Benjamins Publishing, 2018. p. 277-296. DOI: https://doi. org/10.1075/btl.141.14man

O'HAGAN, M.; MANGIRON, C. Game Localization: Translating for the Global Digital Entertainment Industry. Amsterdam; Philadelphia: John Benjamins Publishing, 2013. DOI: https://doi.org/10.1075/btl.106 
PÉREZ, C.; SÁENZ, L. Gender-inclusive Language in Games and Its Localization Challenges. Multilingual, Sandpoint, ID, v. 30, n. 3, p. 32-35, 2019. DOI: https:// doi.org/10.1002/msid.1036

PITKASALO, E.; KETOLA, A. Collaborative Translation in a Virtual Classroom: Proposal for a Course Design. Transletters. International Journal of Translation and Interpreting, Córdoba, v. 1, n. 1, p. 93-119, 2018. Available at: https://www.uco. es/ucopress/ojs/index.php/tl/article/view/11035. Retrieved on: Oct. 02, 2019. STAMENOVA, G. How Localization Changed the Game. Multilingual, Sandpoint, ID, v. 30, n. 3, p. 40-45, 2019.

WENGER, E. Communities of Practice: Learning as a Social System. Systems Thinker, [S.l.], v. 9, n. 5, p. 1-10, 1998. Available at: https://scholar.google.ca/ scholar?hl $=$ en\&as_sdt $=0 \% 2 \mathrm{C} 5 \& \mathrm{q}=$ Communities + of + practice $\% 3 \mathrm{~A}+$ Learning + as $+a+$ social + system\&btnG. Retrieved on: Oct. 22, 2019.

WIJMAN, T. Top 25 Public Game Companies Earned More than $\$ 100$ Billion in 2018. Available at: https://newzoo.com/insights/articles/top-25-public-gamecompanies-earned-more-than-100-billion-in-2018/. Retrieved on: Jun. 13, 2019.

Data de submissão: 5/11/2019. Data de aprovação: 12/8/2020. 